\section{Comparing adult mathematical literacy with PISA students: results of a pilot study}

\author{
Timo Ehmke, Kiel (Germany) \\ Elke Wild, Bielefeld (Germany) \\ Thiemo Müller-Kalhoff, Bielefeld (Germany)
}

\begin{abstract}
In Germany, very little empirical data about the mathematical competence of adults is available. The aim of this study is to test the level of mathematical competence in an adult sample. For this purpose, a mathematics test was constructed using the PISA mathematics framework as a guideline. The test consisted of fourteen public items from the mathematics test in PISA 2000. The study was implemented by carrying out house visits (Germany). The sample was comprised of 64 adults ( $90 \%$ women, age: 41 years). The test results were scaled in the metric of PISA 2000. Compared with the average German student competencies in PISA 2000, the average competency in the adult sample was on the same level as the fifteen-year-old comprehensive secondary school student (at a German Gymnasium). Further analysis shows that the mathematics competency level in the adult sample is positively connected to the individual vocational education degree.
\end{abstract}

Kurzreferat: Über mathematische Kompetenz von Erwachsenen in Deutschland liegen bislang nur wenig empirische Daten vor. Ziel dieser Studie ist es, an einer Stichprobe von Erwachsenen das Niveau von mathematischer Kompetenz zu erfassen. Dazu wurde in Anlehnung an die Rahmenkonzeption des Mathematiktests PISA 2000 ein Test zur Erfassung von mathematischer Grundbildung bei Erwachsenen konzipiert. Der Test bestand aus vierzehn Items des Mathematiktests PISA 2000. Die Durchführung der Studie erfolgte im Rahmen von individuellen Hausbesuchen in Kooperation mit der Universität Bielefeld. Die Stichprobe bestand aus 64 Erwachsen (90\% weiblichen Geschlechts, Altersdurchschnitt 41 Jahre). Im Vergleich mit den Schülerleistung aus PISA 2000, entspricht das durchschnittliche Kompetenzniveau der Erwachsenenstichprobe dem Niveau der fünfzehnjährigen Gymnasiasten in PISA 2000. Weitere Analysen zeigen einen positiven Zusammenhang zwischen Berufabschluss und erreichtem Kompetenzniveau.

ZDM-classification: C40, D60

\section{Introduction}

International large scale assessments such as TIMSS, IGLU and PISA deliver detailed indicators about the mathematical literacy of school students in Germany (Baumert \& Lehmann, 1997; Blum et al., 2004; Klieme et al., 2001; Walther et al., 2003).

Although the alarming German results denote that similar problems exist in adults, research on adult mathematical literacy is given very little importance in Germany.

A summary of literature about the state-of-the-art in research on "adults and mathematics" is given in Maaß \&
Schlöglmann (2000), Jungwirth, Maaß \& Schlöglmann (1995) or Ehmke (2004). In several empirical studies, Maaß \& Schlöglmann analyse to what extent mathematics education in school fulfils the target of being useful for everyday life and occupational demands (Jungwirth, 1994; Jungwirth et al., 1995; Schlöglmann, 1993 1998). Contrary to the intention of the international large scale assessments, which measure mathematics competencies in the sense of mathematical literacy or numeracy, the test items in the studies above are close to the German curriculum and mostly without an application context (see Schlöglmann, 1993, 1998).

The results of Maaß \& Schlöglmann (2000, p. 102) show that $90 \%$ of the adult sample had no problems calculating with small integer numbers. This statement is less valid for adding, subtracting and multiplying with positive decimal numbers. More problems could be seen when using parentheses, when hierarchies of operation should be noted or when one has to deal with very big or very small decimal numbers. Many adults have trouble with negative numbers, fractions or converting between measurement units. Problems also appear with the rule of three and indirect proportionality.

The authors summarise the results of their study (Maaß \& Schlöglmann, 2000, p. 103): With nearly all adults in the sample, it was only the knowledge that was acquired in the first five years of school of which they had good command.

A similar conclusion is also drawn by Heymann (2000, p. 166) in his research summary about the research on life long learning regarding mathematics: a series of studies (Borovcnik, 1981; Cockroft, 1982; Fitzgerald \& Rich, 1981; Heymann, 1996, p. 135f; Knox, 1977; Peschek, 1981; Raatz, 1974) confirm the hypothesis that adults who are not involved in specific mathematics professions use relatively less mathematics in professional and everyday life.

Comparing the items which have been used from Maaß \& Schlöglmann with the PISA items which have been constructed by the mathematical literacy framework, one can say: the items from Maaß \& Schlöglmann are closely orientated to curricular contents and require more technical skills. However, this approach differs from the PISA approach of using items with an everyday or scientific context.

Therefore, no empirical results which analyse the profile of adult mathematical competency with regard to theoretical coherent conception of mathematical literacy are available for Germany. A test approach that is independent of the curriculum is fairer and more valid for adults. In professional and everyday life, technical skills are seldom required. The mathematical modelling of applied problems is needed more often. Because of this research deficit, the question of how far the base curriculum ("Sockel-Curriculum") or the mathematical daily culture ("Fitness für mathematische Alltagskultur") in the everyday community is achieved (Heymann, 2000, p. 167) also remains open. The question about the mathematical competency profile of adults in Germany will be explored and analysed by the pilot study which is described in the following section. 


\section{The pilot study}

\subsection{Objectives}

Against this research background, the objectives of this study can been seen on two levels:

1) The mathematical competency level in the sense of mathematical literacy should be measured in an adult sample. The competency measurement should be linked to the international PISA 2000 metric. Therefore, the German student sample of PISA 2000 could be used as a reference group.

The adult competency level can be set in relation to the PISA sample and one thereby gets an initial indicator as to whether mathematical competency in the adult sample is higher than in the German PISA sample. The research results of Maaß \& Schlöglmann (2000) show that routine mathematical skills, which have been learned in school, decrease as age increases. Whether mathematical competencies in the sense of mathematical literacy (like mathematical modelling of everyday situations) also decrease after school time remains an open question.

2) What was to be explored was whether systematical differences could be found between German adults and PISA students when solving specific item types. For this target a "fair" comparison group from the German PISA sample was identified. One can guess that adults have more problems with items which require technical skills and that adults could solve items which deal with everyday situations more easily.

\subsection{Method and implementation of the study}

\subsubsection{Design of the study}

The data collection was nested in the DFG Project „Die Förderung selbstbestimmter Formen der Lernmotivation in Elternhaus und Schule" (Wild, 1999; Wild \& Remy, 2002), which is part of the framework of the German Research Foundation's (DFG) special programme „Die Bildungsqualität von Schule: Fachliches und fächerübergreifendes Lernen im mathematischnaturwissenschaftlichen Unterricht in Abhängigkeit von schulischen und außerschulischen Kontexten". Within the scope of this longitudinal study, about 250 parents were visited and interviewed in the spring of 2003 for a third time. When the students took part at a mathematics test for a third time, a sub sample $(n=62)$ of these 250 parents could gained for the mathematic competency test. The test was organised and supervised by the test leaders. There was no time limit to the test. The average time for solving the test was about 20 minutes.

\subsubsection{Description of the mathematics test}

The development of the mathematics test was orientated against the German mathematics framework in PISA 2000. The guideline for the development of the national mathematics tests was the systematic consideration of the four content domains: arithmetic, algebra, geometry and stochastic, as well as three types of mathematical tasks: technical skills, calculative modelling, and conceptual modelling (Klieme et al., 2001; Neubrand et al., 2001; Neubrand et al., 2002). The additional German mathematics test in PISA 2000 consisted of 117 items. The test instruments were organised by a rotation design, where each student had to solve between ten and twenty items.

The test time for the adult study was strictly limited. Therefore, no more than fourteen items could be included. The items were chosen according to the following aspects: the content domains arithmetic, algebra and geometry, and the three types of mathematical tasks were equally covered. A broad range of item difficulty was also presented. However, the main constraint was that only PISA items which had already been published could be used at that point in time. This reduced the amount of available items. Table 1 organises the fourteen test items according to the content domains and the three types of mathematical tasks.

Table 1. Number of items classified by content domain and type of mathematical task

\begin{tabular}{|l|l|l|l|l|}
\hline & Arithmetic & Algebra & Geometry & Total \\
\hline $\begin{array}{l}\text { Technical } \\
\text { skills }\end{array}$ & 2 & 0 & 1 & 3 \\
\hline $\begin{array}{l}\text { Calculative } \\
\text { modelling }\end{array}$ & 4 & 3 & 2 & 9 \\
\hline $\begin{array}{l}\text { Conceptual } \\
\text { Modelling }\end{array}$ & 1 & 1 & 0 & 2 \\
\hline Total & 7 & 4 & 3 & 14 \\
\hline
\end{tabular}

The coding of the items was carried out according to the national and international PISA marking guides which provide explicit directions for the coding and scoring of the items. Two independent people coded all the items. If their opinions differed, a third party was consulted.

\subsubsection{Description of the sample}

The sample consisted of $\mathrm{n}=62$ adults (sex: $90.6 \%$ women, $9.3 \%$ men; age: $\mathrm{M}=41.2$ years, $\mathrm{SD}=5.1$ years; Origin: $95.2 \%$ born and brought up in Germany, all others have been in Germany for more than 14 years). The adults are the parents of $7^{\text {th }}$ grade students. The parents had already been surveyed within a longitudinal study. This was the third visit and questionnaire investigation within three years.

In the following section, we characterise the economic, social and cultural background of the families who took part in this study. We describe the school graduation, vocational education and the occupation.

With regard to the highest school graduation, $8.06 \%$ got a lower secondary school degree (Hauptschulabschluss), $45.16 \%$ a intermediate secondary school degree (Realschulabschluss) and $12.90 \%$ a technical college degree of higher education (Fachhochschulabschluss). About one third of the respondents $(33.87 \%)$ completed a comprehensive secondary school examination (Abitur) (Figure 1). 
Figure 1. Description of the school degrees in the adult sample

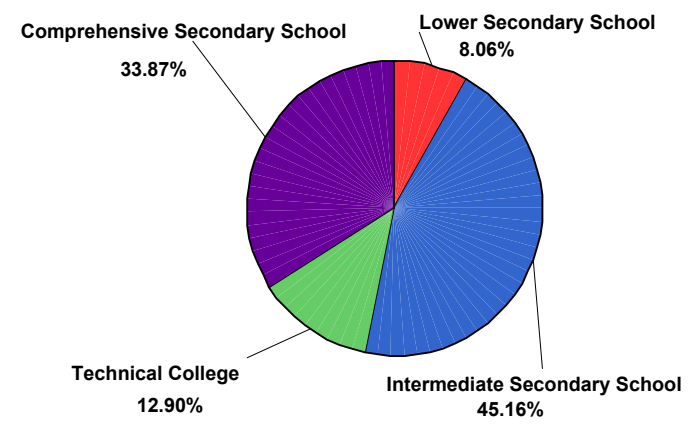

A similar picture concerning the highest vocational education can be seen in figure 2 : only $3.2 \%$ of the adult sample doesn't have a degree. Most of the people have done an apprenticeship at the highest level (45,76\%). $13.56 \%$ have a degree from a vocational school and $11.86 \%$ work as a foreman or technician. About one quarter are university graduates $(28.81 \%)$.

Figure 2. Description of the highest vocational education degrees in the adult sample

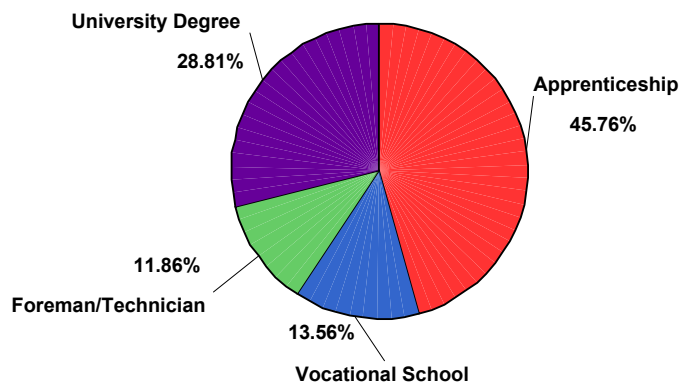

Therefore, one third of the sample comprises people who have a higher educational background. This fact is reflected in the distribution of the occupational groups (figure 3). A quarter of the interviewees work as academics or freelancers $(26.42 \%)$. Additionally, $20.75 \%$ are people who work in a higher office position or as a leading employee. The biggest part of the sample $(45.28 \%)$ works as qualified and executive employees. Also, there are $7.55 \%$ skilled workers.

Figure 3. Description of the occupation in the adult sample

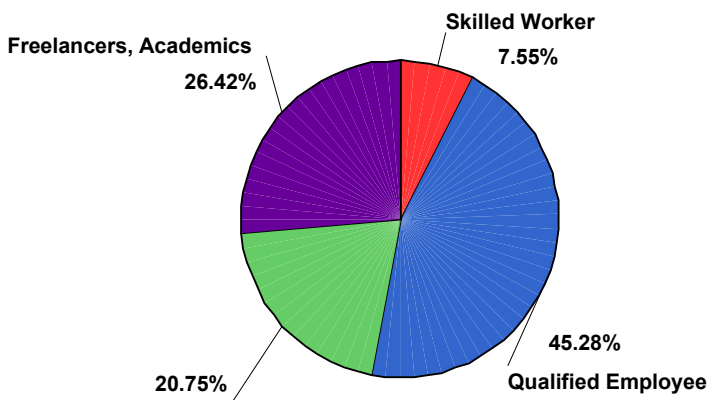

Higher Officer Position, Leading Employee

\section{Results and interpretation}

In order to describe the results, we have first presented the solution frequencies of the fourteen items in total. In a second step, we have compared the mean scores and standard deviations of the adult sample with the results of students from Germany who took part in PISA 2000. In a third step we analyse items specific differences between adults and PISA students.

\subsection{Score distribution in the adult sample}

Figure 4 shows the score distribution of $n=62$ adults. The average mean value was 10.6 score points $(\mathrm{SD}=$ 3.52 ) out of a maximum of 16 points. The average solution frequency was about $p=0.66$. Therefore, the difficulty level of the test was not too easy and not too hard $(0.20<\mathrm{p}<0.80)$.

Figure 4. Distribution of score points achieved (max. 16)

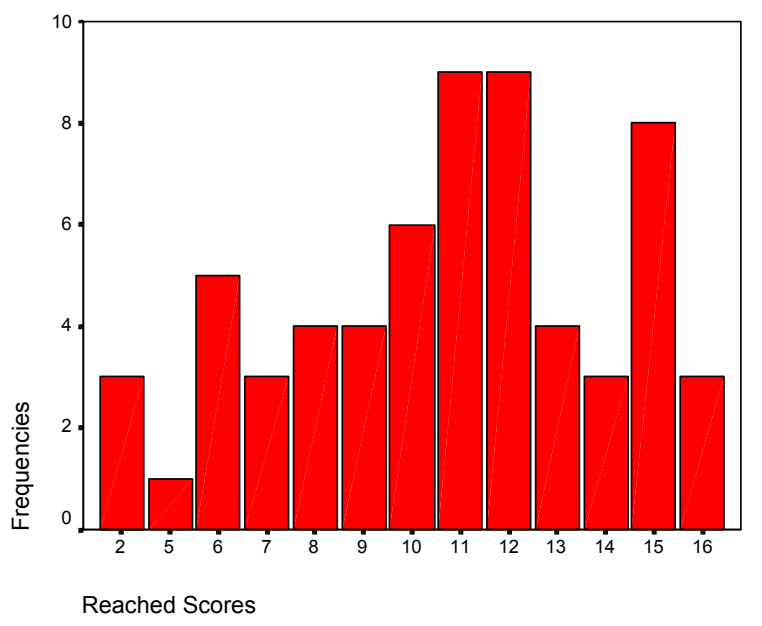

\subsection{Comparison of the competency values between the adult sample and students in PISA}

To get an indicator for the competency level of the adult sample, the test results of the 15-year-old German students in PISA $(n=5.073)$ were taken as a reference measure. The personal ability values of the adult sample could be linked to the PISA competency scale in mathematics because the items in the mathematics test in this study are from the 117 national and international mathematics test in PISA. The linking could be achieved by scaling (Rasch model) with fixed item parameters (Adams, 2002; Rasch, 1960). Afterwards, the scaled personal ability values were transformed to a mean value of 100 score points and a standard deviation of 30 score points, which was the metric of the additional PISA mathematics test in Germany. For the implementation and parameter estimation, the statistics software ConQuest (Wu et al., 1997) was used. The same software is used for the scaling of the PISA data.

For the following data analysis, we used the EAP values $(\mathrm{EAP}=$ Expected Aposteriori Predictor) as personal ability parameters which were estimated with ConQuest (Mislevy et al., 1992). As a result of this procedure, we got an average competency value of $\mathrm{M}=121(\mathrm{SD}=32)$ for the adult sample. Therefore, the 
average test performance of the adults is about one third standard deviations higher than the average student performance of the German PISA sample. However, this comparison is not very significant because the German PISA students at large are not an appropriate comparison group. However, if we differentiate within the German PISA sample between the different school types, one gets better comparison groups. Figure 5 shows the mean and standard deviations of the German PISA students, differentiated by school type, compared with the mean of the adult sample. Students in three school types were differentiated: lower secondary school (in Germany: Hauptschule; label: PISA-HS), intermediate secondary school (in Germany: Realschule; PISA-RS) and comprehensive secondary school (in Germany: Gymnasium; PISA-GY). In figure 5 one can see that the average competency level in mathematics is on the same level as the fifteen-year-old students at a comprehensive secondary school $(\mathrm{M}=123, \mathrm{SD}=24)$. The mean of the students in the two other school types is lower (lower secondary school: $\mathrm{M}=77, \mathrm{SD}=22$; intermediate secondary school: $\mathrm{M}=97, \mathrm{SD}=24)$. The standard deviation $(\mathrm{SD}=32)$ in the adult sample is higher than in the PISA sample.

Figure 5. Mathematics competency in the adult sample compared to the student performance of the German PISA sample (three school levels)

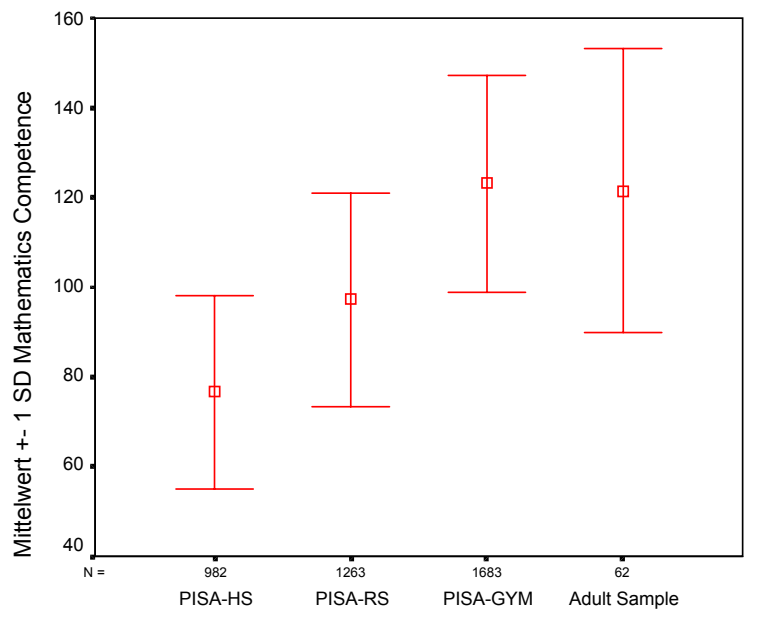

To get more homogeneous groups of adults, we distinguished between two groups of adults: a) people with a lower secondary school degree or a degree from a intermediate secondary school (label: Adults HS/RS) and b) people with a technical college degree of higher education or a comprehensive secondary school degree (label: Adults $\mathrm{FH} / \mathrm{GY}$ ). The mean mathematics competence is shown in figure 6.

Adults in the second group (FH/GY) reach about one half standard deviation from higher mathematics performance $(M=134, S D=29)$ than the PISA students at a comprehensive secondary school (PISA-GY). However, this result could be expected by the fact that adults in this group had three or four years more of mathematics lessons in school and an additional vocational education.
What is more surprising is the fact that the adults with a lower secondary school degree or a degree from a intermediate secondary school show a lower performance $(\mathrm{M}=111, \mathrm{SD}=33)$ than fifteen-year-old students at the comprehensive secondary school.

Figure 7 compares the mean performance of four occupation groups from the adult sample to the PISA sub sample (students at a comprehensive secondary school). Adults with an apprenticeship as a vocational education degree reach a competency level $(\mathrm{M}=113, \mathrm{SD}=27)$ that lies between the average mathematics performance of intermediate secondary school students and students from a comprehensive secondary school in the German PISA sample.

Figure 6. Mathematics competency in the adult sample in two groups compared to the student performance of the German PISA sample (three school levels)

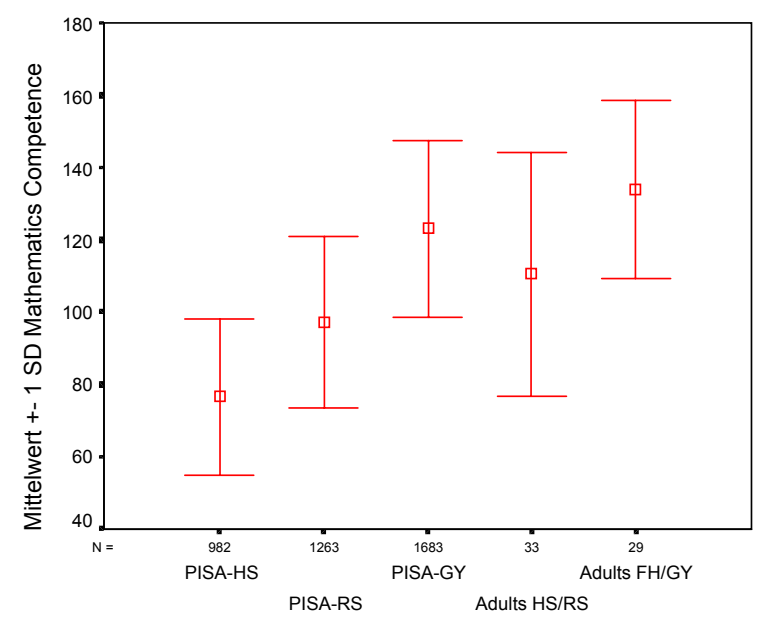

Adults with a higher professional occupation show higher performance in the mathematics test: vocational school degree $(M=134, S D=25)$, foreman or technician $(\mathrm{M}=135, \mathrm{SD}=17)$, and people with a university degree $(\mathrm{M}=136, \mathrm{SD}=27)$. This result validates the analysis in figure 6: people with a higher school degree reach a higher competency score than the PISA reference group.

Figure 7. Mathematics competency in the adult sample differentiated by the degree of vocational education

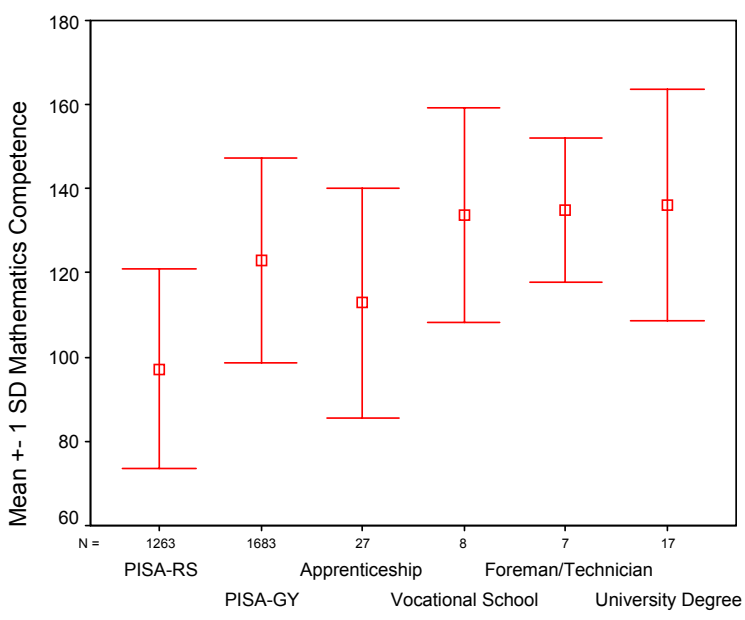




\subsection{Analysis of group-specific strength and weakness}

The second research question of this study was to analyse whether there are group-specific differences between students and adults in solving single items. A first assumption is that one can most likely observe differences in tasks which require technical skills in a purely mathematical item context.

Again, we used the fifteen-year-old German PISA students at a comprehensive secondary school (PISAGY) as a comparison group because these students have a comparable competency level in mathematics. To find out in which items there are differences between adults and students, we compared the differences of the group mean for each item. Additionally, a t-test shows whether the mean differences are statistically significant. Because of the multi matrix test design in PISA 2000, the number $\mathrm{n}$ of cases per item ranges $(148 \leq \mathrm{n} \leq 1.436)$.

Table 2 compares the solution frequencies of both groups for all items. The fourth column shows the results of the t-test. This analysis delivers four items which have group-specific item difficulties. The three items Farms b), Apples b) und Fractions (Bruchrechnung) are easier for the students, whereas the item Rent (Miete) is significantly easier for the adults.

In the following we discuss the four items in detail. The items are included in the appendix A-D. Where possible, we have given some information about the way in which the solution was found.

Table 2. Comparison of the solution frequencies between the adult sample and the PISA reference group

\begin{tabular}{|c|c|c|c|}
\hline Item name & \begin{tabular}{|l} 
Mean \\
Adult
\end{tabular} & \begin{tabular}{|l} 
Mean \\
PISA-GY
\end{tabular} & t-Test \\
\hline $\begin{array}{l}\text { Farms a) } \\
(\text { Bauernhof) }\end{array}$ & 0.74 & 0.77 & n. s. \\
\hline Farms b) & 0.53 & 0.74 & $\begin{array}{l}\mathrm{t}(\mathrm{df}=312)=3.28 \\
\mathrm{p}<.001\end{array}$ \\
\hline $\begin{array}{l}\text { Racing car a) } \\
\text { (Rennwagen) }\end{array}$ & 0.82 & 0.84 & n. s. \\
\hline Racing car b) & 0.92 & 0.97 & n. s. \\
\hline Racing car c) & 0.89 & 0.96 & n. s. \\
\hline Racing car d) & 0.35 & 0.42 & n. s. \\
\hline $\begin{array}{l}\text { Apples a) } \\
(\text { Äpfel })\end{array}$ & 0.69 & 0.75 & n. s. \\
\hline Apples b) & 0.40 & 0.73 & $\begin{array}{l}\mathrm{t}(\mathrm{df}=454)=5.21 \\
\mathrm{p}<.001\end{array}$ \\
\hline Apples c) & 0.33 & 0.35 & n. s. \\
\hline Rent (Miete) & 0.68 & 0.40 & $\begin{array}{l}\mathrm{t}(\mathrm{df}=208)=3.78 \\
\mathrm{p}<.001\end{array}$ \\
\hline Bap (Brötchen) & 0.94 & 0.96 & n. s. \\
\hline $\begin{array}{l}\text { Fractions } \\
\text { (Bruchrechnung) }\end{array}$ & 0.58 & 0.89 & $\mid \begin{array}{l}t(d f=219)=5.43 \\
p<.001\end{array}$ \\
\hline $\begin{array}{l}\text { Rectangle } \\
\text { (Rechteck) }\end{array}$ & 0.90 & 0.95 & n. s. \\
\hline $\begin{array}{l}\text { Glass factory } 1 \\
\text { (Glasfabrik 1) }\end{array}$ & 0.85 & 0.81 & n. s. \\
\hline
\end{tabular}

\section{a) Item Rent}

The item Rent was the only one that was solved more often by adults than by students. The item context deals with an everyday life problem. The high solution rate in the adult sample can probably be attributed to this fact. Adults can gain from their longer experience of everyday life which students don't have.

Regarding the manner in which the adults solved this task, most of them used three calculation steps to develop the solution:

$$
\begin{aligned}
& \text { 1. 1985: } 1000 .-\mathrm{DM} \\
& \text { 2. 1990: } 1000 .-\mathrm{DM}+200 .-\mathrm{DM}=1200 .-\mathrm{DM} \\
& \text { 3. 1995: } 1200 .-\mathrm{DM}+240 .-\mathrm{DM}=1440 .-\mathrm{DM}
\end{aligned}
$$

A connected solution in one step, for example, 1000.DM x 1,2 = 1440.- DM, was not chosen.

A mistake that was frequently made was not to bear in mind the increased base value after five years. The adults calculated with a 40 percent increase of the rent within 10 years. This led to a price of 1400.- DM. Another frequently occurring mistake was to assume that the rent in 1985 had already increased to 1200 .- DM. Then one took three annual raises into account. Adults seldom made mistakes concerning the decimal point in the number system, for example with 20.- DM instead of 200.- DM.

\section{b) Item Farms b)}

The solution frequency for the second part of the unit Farms was about 20 percent higher in the reference group than in the adult sample. An error analysis for this item is not easy because a closed response format was used. The question/item only asked for a measured value. One can assume that one part of the adults did not have an adequate solution idea by the fact that there were fewer incorrect solutions but a lot of invalid responses, for example crossing the response field.

To solve this item correctly, one needs knowledge about the theorem on intersecting lines or about the centre line of a triangle (Klieme et al., 2001, p. 151). Both of these theorems could be assigned to the field of declarative knowledge. It is obvious that the adults had/have less opportunity to use this knowledge.

Of course, it would be possible to solve this item by estimating but only a few of the incorrect responses suggest that they are the result of estimation. Another explanation for the high difficulty of the item could be the fact that this item is included in a context that could be described as not being very close to everyday life.

\section{c) Item Fractions}

This item was solved by 90 percent of the PISA secondary comprehensive school students but only by two thirds of the adult sample. The item format was multiple choice so it is possible to analyse the distractors. The adults only chose two of the four possible responses: $270(29 \%)$ and $30(10 \%)$. It is obvious that the item context has no connection to everyday life. This context is a purely mathematical one. In order to solve this question correctly, one needs to remember to divide fractions by using the multiplicative inverse of one fraction. The relatively high percentage of wrong 
responses lets us assume that one third of the adults could not apply this rule correctly or could not even remember it.

\section{d) Item Apples b)}

The unit Apples comprises three parts. On average, three thirds of the PISA reference group could solve all three items. In the adult sample, it is noticeable that item part b) is solved less often than in the reference group. Again, the artificial context which comes only from mathematics in this item seems to hinder adults from solving this item.

Regarding the manner in which the solution was reached, three different ways were used. The first variant was most popular: solving the equation $n^{2}=8 n$ by calculation. The task was solved less often by continuing the table in item Farms a) or by simply "looking". It was not possible to analyse wrong responses because there were nearly none. Most of the incorrect scores were coded as invalid. This is the case when the adults just draw a line through the answer field.

\subsection{In Summary}

With respect to the small number of items and the small sample size, we must judge the analysed mean differences as explorative. However, the tendency shows that students can deal with some kinds of mathematics items better than adults. This was clear for the items Fractions and Farms b); for the successful solution both require some knowledge about geometrical theorems or technical skills. The task, which was solved better by adults, was characterised by a close relation to mathematics in everday life. This could be seen in the item Rent. A second item with an everyday life context was the item Bap. But the item difficulty was too low, so that no differences could be identified.

\section{Discussion}

The study has shown that the competency level in mathematics in the adult sample was comparable to the performance of the fifteen-year-old German PISA students visiting a comprehensive secondary school. A differentiation by the degree of school education showed a lower test performance for adults with a degree from a lower secondary school or an intermediate secondary school than for people who have a school degree from a higher level.

The competency level of the first group of adults was slightly higher than the competency level of the PISA students going to a lower secondary school or an intermediate secondary school. It is obvious that the vocational and professional development and everyday life experience (learning with their own children) have led to an increase in competency.

For this reason, we assume that the adults in the sample had a similar competency level 25 years ago to the PISA sub sample in 2000. This is an assumption which is difficult to hold - one only needs to think about the increasing distribution of pocket calculators.

An increased mathematics competency was observed in the sub sample with upper vocational education degrees: adults with a university degree, foreman \& technicians and people with a vocational school degree. The average competency level was about one third higher than in the PISA reference sub sample. Again, this finding is intuitively comprehensible. A longer period of school education and professional development is the cause for this. Similar results in adults learning mathematics could be found in Karsenty (2002). These results support the assumption that even though the school education is finished, a slight increase in mathematics competency can be expected.

By linking the competency scale used for the adult sample to the competency scale used in PISA 2000, one can analyse whether the adult sample reaches an a priori defined performance level.

One target of school mathematics is to make sure that the students reach a certain competency level. This comprises not only technical skills, it also means developing the ability to deal with mathematical models (Heymann, 1996; Winter, 1995). In the national German PISA 2000 report, a "sufficient" level for mathematical literacy was defined at a competency level 3 (Klieme et al., 2001, p. 161). Therefore, all students who reach a competency value greater than 512 points on the international competency scale (OECD: $\mathrm{M}=500$, $\mathrm{SD}=100)$ are on level 3. All students below that level are described as having insufficient mathematics competency.

If we apply this measurement to the adult sample, we get an indication of the proportion of adults in the sample who do not reach this minimum level. For this reason, the competency values have been transformed ${ }^{1}$ into the international PISA metric.

After doing this, the adult sub sample with the two lower school degrees (lower secondary school and intermediate secondary school) have a mean performance value $(\mathrm{M}=490)$ that is below competency level 3 . In the German PISA 2000 report, the competency level 2 (421 511 points) is described as follows (Klieme et al., 2001, p. 160):

On this level, easy conceptual modelling that is embedded in a context outside mathematics can be conducted. People on this competency level can find out the adequate solution if some are presented and if graphics, tables or drawings provide a structure which supports the modelling process. Only knowledge obtained in the first four years of school is reliaby accessible at this competency level.

$$
{ }^{1} \theta_{i}=S D_{i}\left(\frac{\theta_{n}-M_{n}}{S D_{n}}\right)+M_{i},
$$

with $\theta_{\mathrm{i}}=$ personal ability value on international scale, $\theta_{\mathrm{n}}:=$ personal ability value on national scale, $\mathrm{M}_{\mathrm{n}}=100$ (mean on national competency scale), $\mathrm{M}_{\mathrm{i}}=500$ (mean on international competency scale), $\mathrm{SD}_{\mathrm{n}}=30$ (standard deviation on national competency scale), $\mathrm{SD}_{\mathrm{i}}=100 \quad$ (standard deviation on international competency scale). 
The adult sub sample with the two higher school degrees (technical college degree or a comprehensive secondary school degree) reach on average a mean value $(\mathrm{M}=577)$ on competency level 3 (512-603 points). The third level could be characterised as follows:

Level 3 made in multiple aspects a qualitative step higher compared with level 2. People on this level possess over simplified content from secondary school. They are able to connect mathematical knowledge from different domains and use it to solve problems if visual illustrations support the problem solving process.

These descriptions of the empirically acquired competency levels are primarily aimed at the target group of fifteen-year-old students. The textual description cannot be transferred to the target group of adults without problems. However, the finding that half of the adult sample showed a performance on competency level 2 and below indicates a not insignificant proportion of adults with insufficient mathematics competencies.

In order to establish a relationship to the findings of Maaß \& Schlöglmann (2000), we can also state that adults who have deficits in solving traditional school mathematics items are not necessarily incapable of dealing with mathematics in everyday life. Wedege (1999) showed that the context of an item is important for adults in determining whether they can solve a problem or not. The context can be within mathematics or a context outside mathematics. Besides that, the context can be related to the particular situation which is activated in an item. This is labelled as situation context. A popular example for this is presented in the studies of Nunes et al. (1993). They worked with children in Brazil. The kids(s.o.) were able to solve mathematical problems with a context of street affairs. However, structural isomorphic items in a school context could not be solved successfully.

Depending on the item context, we also found differences between students and adults concerning the item difficulty in this study. The fact that the item Rent was easier for the adult sample and that the item Fraction was less difficult for students can be seen as evidence for this. The distinction between mathematical school knowledge and mathematical literacy with a higher relation to applied contexts is very important when evaluating adult mathematics competency and should be taken into account in further studies. The results of Maaß \& Schlöglmann (2000) suggest that with increasing age, mathematics abilities have a tendency to decrease. With regard to the findings of this study, this is more valid for items which require technical skills. When measuring mathematics competency with items that are taken from an everyday life situation, one can expect an increase in mathematics competence after school age.

When considering this result, we must reconsider the methodological procedure critically, where we used the fixed item parameters of the PISA student sample to estimate the adult ability values. With this procedure, all the items which are easier for students will show a tendency to underestimate the adult's ability in the adult sample. For all the items that are easier for the adults, there will be a tendency to overestimate the person parameter. The findings of this study must be interpreted against this background. Furthermore, one has to bear in mind that the sample size was small and the gender proportion was not equal. Therefore, the findings must be seen as explorative.

The described study is the result of a pilot study for the project „Mathematische Kompetenz bei Erwachsenen Eine Studie an Eltern von PISA-Schülerinnen und Schülern“ (Ehmke, 2003), which was founded by the German Research Foundation (DFG). In the main study, adult mathematical competency will be measured in a sub sample of parents from students who took part in the PISA study in Germany. Besides the level of mathematical literacy in the adult sample, we will analyse the connection between the mathematics competency of parents and their children.

\section{References}

Adams, R. (2002). Scaling PISA Cognitive Data. In R. Adams \& M. L. Wu (Hrsg.), PISA 2000. Technical Report (S. 99108). Paris: OECD.

Baumert, J., \& Lehmann, R. (Hrsg.). (1997). TIMSS Mathematisch-naturwissenschaftlicher Unterricht im internationalen Vergleich. Opladen: Leske \& Budrich.

Blum, W., Neubrand, M., Ehmke, T., Senkbeil, M., Jordan, A., Ulfig, F., \& Carstensen, H. C. (2004). Mathematische Kompetenz. In U. Schiefele (Hrsg.), Pisa 2003. Der Bildungsstand der Jugendlichen in Deutschland - Ergebnisse des zweiten internationalen Vergleichs (S. 47-92). Münster, New York, Münschen, Berlin: Waxmann.

Borovcnik, M. (1981). Mathematik in der beruflichen Praxis. Ergebnisse eines Forschungsprojektes. Wien, Stuttgart: Hölder-Pichler-Tempsky, Teubner.

Cockroft, W. H. (1982). Mathematics counts ("CockroftReport"). Report of the Committee of Inquiry into Teaching of Mathematics in School under the Chairmanship of Dr. W. H. Cockroft. London: Her majesty's Stationary Office.

Ehmke, T. (2003). Mathematical Literacy bei Erwachsenen: Eine Studie an Eltern von PISA-Schülerinnen und -Schülern (DFG-Antrag auf Sachbeihilfe). Kiel: Leibniz-Institut für die Pädagogik der Naturwissenschaften.

Ehmke, T. (2004). Mathematische Kompetenz bei Erwachsenen. Ein Überblick zum Stand der empirischen Forschung, Beiträge zum Mathematikunterricht. Hildesheim: Franzbecker. 145-148.

Fitzgerald, A., \& Rich, K. M. (1981). Mathematics in Employment. Bath: University of Bath.

Heymann, H.-W. (1996). Allgemeinbildung und Mathematik. Weinheim, Basel: Beltz.

Heymann, H.-W. (2000). Lebenslanges Lernen unter Berücksichtigung von Forschungen zum Mathematikunterricht. In F. Achtenhagen \& W. Lempert (Hrsg.), Lebenslanges Lernen im Beruf - seine Grundlegung im Kindes- und Jugendalter. Band 4: Formen und Inhalte von Lernprozessen (S. 164-174). Opladen: Leske + Budrich.

Jungwirth, H. (1994). Erwachsene und Mathematik - eine reife Beziehung? Mathematica Didactica. Zeitschrift für Didaktik der Mathematik, 17(1), 69-89. 
Jungwirth, H., Maßß, J., \& Schlöglmann, W. (1995). Abschlussbericht zum Forschungsprojekt: Mathematik in der Weiterbildung. Linz: Universität Linz.

Karsenty, R. (2002). What do Adults remember from their High School Mathematics? The Case of Linear Functions. Educational Studies in Mathematics, 51, 117-144.

Klieme, E., Neubrand, M., \& Lüdtke, O. (2001). Mathematische Grundbildung: Testkonzeption und Ergebnisse. In J. Baumert, E. Klieme, M. Neubrand, M. Prenzel, U. Schiefele, W. Schneider, P. Stanat, K.-J. Tillmann \& M. Weiß (Hrsg.), PISA 2000. Basiskompetenzen von Schülerinnen und Schülern im internationalen Vergleich (S. 139-190). Opladen: Leske + Budrich.

Knox, C. (1977). Numeracy and school leavers. A survey of employer's needs. Sheffield: Sheffield Region Centre for Science \& Technology.

Maaß, J., \& Schlöglmann, W. (2000). Erwachsene und Mathematik. Mathematica Didactica. Zeitschrift für Didaktik der Mathematik, 23(2), 95-106.

Mislevy, R. J., Beaton, A. E., Kaplan, B., \& Sheehan, K. M. (1992). Estimating population characteristics from sparse matrix samples of item responses. Journal of Educational Measurement, 29, 133-161.

Neubrand, M., Biehler, R., Blum, W., Cohors-Fresenburg, E., Flade, L., Knoche, N., Lind, D., Löding, W., Möller, G., \& Wynands, A. (2001). Grundlagen der Ergänzung des internationalen PISA-Mathematik-Tests in der deutschen Zusatzerhebung. Zentralblatt für Didaktik der Mathematik, 33(2), 33-45.

Neubrand, M., Klieme, E., Lüdtke, O., \& Neubrand, J. (2002). Kompetenzstufen und Schwierigkeitsmodelle für den PISATest zur mathematischen Grundbildung. Unterrichtswissenschaft. Zeitschrift für Lernforschung, 30(1), 100-119.

Nunes, T., Schliemann, A. D., \& Carraher, D. W. (1993). Street mathematics and school mathematics. Cambridge: Cambridge University Press.

Peschek, W. (1981). Mathematikunterricht und Qualifizierung. Journal für Mathematik-Didaktik, 2, 249-279.

Raatz, U. (1974). Mathematik am Arbeitsplatz - zwei empirische Untersuchungen. Materialien zu VHS-Zertifikaten, 15.

Rasch, G. (1960). Probabilistic models for some intelligence and attainment tests. Copenhagen: Nielsen \& Lydice.

Schlöglmann, W. (1993). Mathematikkenntnisse von Erwachsenen. Beiträge zum Mathematikunterricht, 319-322.

Schlöglmann, W. (1998). Was bleibt vom schulischen Mathematiklernen - Mathematikkenntnisse bei Erwachsenen. Mathematica Didactica. Zeitschrift für Didaktik der Mathematik, 21(1), 86-107.

Walther, G., Geiser, H., Langeheine, R., \& Lobemeier, K. (2003). Mathematische Kompetenzen am Ende der vierten Jahrgangsstufe. In W. Bos, E.-M. Lankes, M. Prenzel, K. Schwippert, G. Walther \& R. Valtin (Hrsg.), Erste Ergebnisse aus IGLU. Schülerleistungen am Ende der vierten Jahrgangsstufe im internationalen Vergleich (S. 189-226). Münster, New York, München, Berlin: Waxmann.

Wedege, T. (1999). To know - or not to know - mathematics, that is a question of context. Educational Studies in Mathematics, 39(1), 205-227.

Wild, E. (1999). Die Förderung selbstbestimmter Formen der Lernmotivation in Elternhaus und Schule (DFG-Antrag auf Sachbeihilfe). Mannheim: Lehrstuhl Erziehungswissenschaft II.

Wild, E., \& Remy, K. (2002). Quantität und Qualität der elterlichen Hausaufgabenbetreuung von Drittklässlern in Mathematik. Zeitschrift für Pädagogik, 45. Beiheft, 276-290.
Winter, H. (1995). Mathematikunterricht und Allgemeinbildung. Mitteilungen der Gesellschaft für Didaktik der Mathematik, 61, 37-46.

Wu, M. L., Adams, R. J., \& Wilson, M. R. (1997). ConQuest: Multi-Aspect Software. Camberwell, Vic.: Australian Council for Educational Research.

\section{Author}

Ehmke, Timo, Dr., Leibniz-Institut für die Pädagogik der Naturwissenschaften (IPN) an der Universität Kiel, Olshausenstr. 62, D-24098 Kiel, Germany.

Email: ehmke@ipn.uni-kiel.de

Wild, Elke, Prof. Dr., Universität Bielefeld, Fakultät für Psychologie und Sportwissenschafen, Abteilung Psychologie, Postfach 1001 31, D - 33501 Bielefeld, Germany.

Müller-Kalhoff, Thiemo, Universität Bielefeld, Fakultät für Psychologie und Sportwissenschafen, Abteilung Psychologie, Postfach 1001 31, D - 33501 Bielefeld, Germany.

\section{Appendix}

\section{A) Item Farms}

Here you see a photograph of a farmhouse with a roof in the shape of a pyramid.

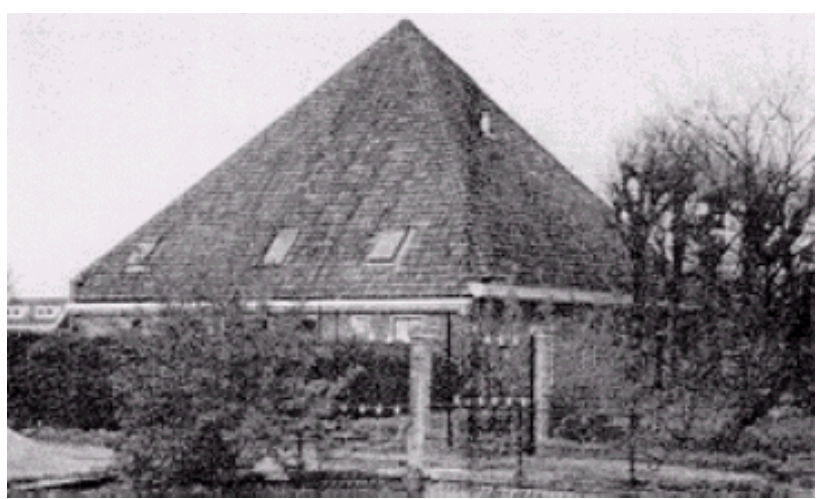

Below is a student's mathematical model of the farmhouse roof with measurements added.

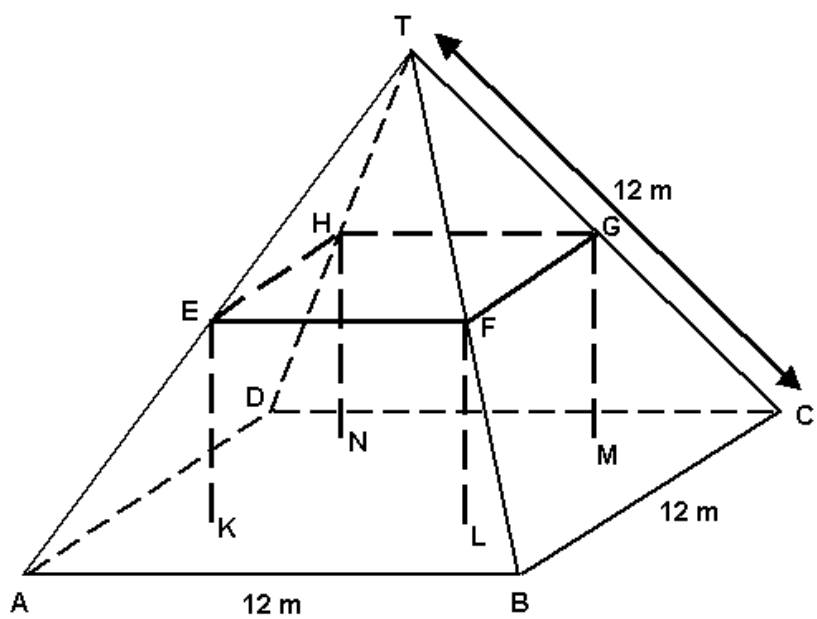

The attic floor, ABCD in the model, is a square. The beams that support the roof are the edges of a block (rectangular prism) EFGHKLMN. E is the middle of $\underline{\mathrm{AT}}$, 
$\mathrm{F}$ is the middle of $\underline{\mathrm{BT}}, \mathrm{G}$ is the middle of $\underline{\mathrm{CT}}$ and $\mathrm{H}$ is the middle of DT. All the edges of the pyramid in the model have a length of $12 \mathrm{~m}$.

a) Calculate the area of the attic floor $\mathrm{ABCD}$. The area of the attic floor $\mathrm{ABCD}=$ $\mathrm{m}^{2}$.

b) Calculate the length of EF, one of the horizontal edges of the block. The length of $\mathrm{EF}=$ $\mathrm{m}$

B) Item Rent

The rent for a $70 \mathrm{~m}^{2}$ flat in a big city was $1000 \mathrm{DM}$ per month in 1985 . Since 1985 the rent has increased every five years by about $20 \%$. How much is the monthly rent in 1995? Write down how you calculate your answer.

C) Item Fraction

Calculate:

$$
90: \frac{1}{3}=
$$

Mark the correct solution:

$$
\begin{array}{cr}
\square & 270 \\
\square & 135 \\
\square & 30 \\
\square & \frac{1}{30} \\
\square & \frac{1}{270}
\end{array}
$$

D) Item Apples

A farmer plants apple trees in a square pattern. In order to

\begin{tabular}{|c|c|c|c|c|c|c|c|}
\hline \multicolumn{3}{|c|}{$\mathrm{n}=1$} & \multicolumn{5}{|c|}{$\mathrm{n}=2$} \\
\hline$x$ & $x$ & $x$ & $x$ & $x$ & $x$ & $X$ & $x$ \\
\hline$x$ & 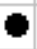 & $x$ & $x$ & 0 & & 0 & $x$ \\
\hline$x$ & $x$ & $x$ & $x$ & & & & $x$ \\
\hline & & & $x$ & 0 & & 0 & $x$ \\
\hline & & & $x$ & $x$ & $x$ & $x$ & $x$ \\
\hline
\end{tabular}
protect the trees against the wind he plants conifers all around the orchard.

Here you see a diagram of this situation where you can see the pattern of apple trees and conifers for any number (n) of rows of apple trees:

$\mathbf{x}=$ conifer

= apple tree $\mathrm{n}=3$

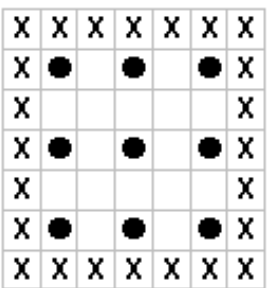

$n=4$

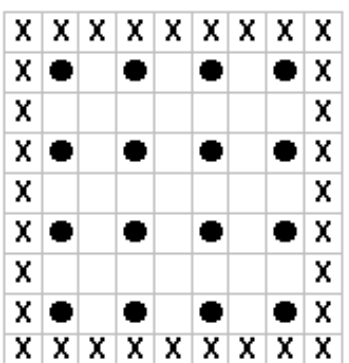

a) Complete the table

\begin{tabular}{|l|l|l|}
\hline $\mathrm{n}$ & $\begin{array}{l}\text { Number of } \\
\text { apple trees }\end{array}$ & $\begin{array}{l}\text { Number of } \\
\text { conifers }\end{array}$ \\
\hline 1 & 1 & 8 \\
\hline 2 & 4 & \\
\hline 3 & & \\
\hline 4 & & \\
\hline 5 & & \\
\hline
\end{tabular}

b) There are two formulae you can use to calculate the number of apple trees and the number of conifers for the pattern described above:

Number of apple trees $=n^{2}$

Number of conifers $=8 n$

where $n$ is the number of rows of apple trees.

There is a value for $n$ for which the number of apple trees equals the number of conifers. Find the value of $n$ and show your method for calculating this.

c) Suppose the farmer wants to make a much larger orchard with many rows of trees. As the farmer makes the orchard bigger, which will increase more quickly: the number of apple trees or the number of conifers? Explain how you found your answer. 